\title{
Interoperability in the e-Government Context
}

Marc Novakouski

Grace A. Lewis

January 2012

TECHNICAL NOTE

CMU/SEI-2011-TN-014

Research, Technology, and System Solutions Program

http://www.sei.cmu.edu

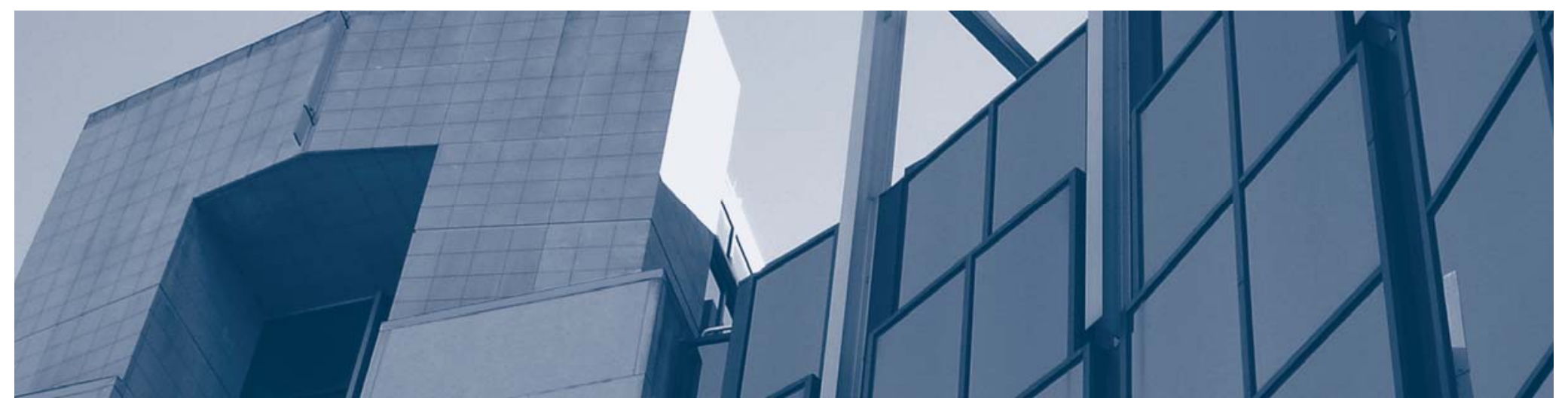


Copyright 2012 Carnegie Mellon University.

This material is based upon work funded and supported by the United States Department of Defense under Contract No. FA8721-05-C-0003 with Carnegie Mellon University for the operation of the Software Engineering Institute, a federally funded research and development center.

Any opinions, findings and conclusions or recommendations expressed in this material are those of the author(s) and do not necessarily reflect the views of the United States Department of Defense.

This report was prepared for the

SEI Administrative Agent

ESC/CAA

20 Schilling Circle, Building 1305, $3^{\text {rd }}$ Floor

Hanscom AFB, MA 01731-2125

\section{NO WARRANTY}

THIS CARNEGIE MELLON UNIVERSITY AND SOFTWARE ENGINEERING INSTITUTE MATERIAL IS FURNISHED ON AN “AS-IS” BASIS. CARNEGIE MELLON UNIVERSITY MAKES NO WARRANTIES OF ANY KIND, EITHER EXPRESSED OR IMPLIED, AS TO ANY MATTER INCLUDING, BUT NOT LIMITED TO, WARRANTY OF FITNESS FOR PURPOSE OR MERCHANTABILITY, EXCLUSIVITY, OR RESULTS OBTAINED FROM USE OF THE MATERIAL. CARNEGIE MELLON UNIVERSITY DOES NOT MAKE ANY WARRANTY OF ANY KIND WITH RESPECT TO FREEDOM FROM PATENT, TRADEMARK, OR COPYRIGHT INFRINGEMENT.

This material has been approved for public release and unlimited distribution except as restricted below.

Internal use:* Permission to reproduce this material and to prepare derivative works from this material for internal use is granted, provided the copyright and "No Warranty" statements are included with all reproductions and derivative works.

External use:* This material may be reproduced in its entirety, without modification, and freely distributed in written or electronic form without requesting formal permission. Permission is required for any other external and/or commercial use. Requests for permission should be directed to the Software Engineering Institute at permission@sei.cmu.edu.

* These restrictions do not apply to U.S. government entities. 


\section{Table of Contents}

$\begin{array}{ll}\text { Abstract } & \mathbf{v}\end{array}$

$\begin{array}{llr}1 & \text { Introduction } & 1\end{array}$

2 The e-Government Context 2

2.1 What Is e-Government? 2

2.2 What Is e-Government Interoperability? $\quad 2$

2.3 What Are the Benefits of Interoperability in an e-Government Context? 3

2.4 Why Is e-Government Interoperability Important?

3 The Interoperability Problem $\quad 5$

3.1 What Is Interoperability?

$\begin{array}{lll}3.2 & \text { Interoperability Models } & 5\end{array}$

$4 \quad$ A Proposed Model for Understanding Interoperability in the e-Government Context 7

$\begin{array}{lll}4.1 & \text { Interoperability Goals } & 7\end{array}$

$\begin{array}{lll}\text { 4.1.1 Data Exchange } & 7\end{array}$

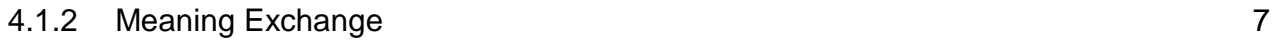

$\begin{array}{lll}\text { 4.1.3 Process Agreement } & 8\end{array}$

$\begin{array}{llr}4.2 & \text { Interoperability Levels } & 8\end{array}$

4.2.1 Technical Interoperability 9

4.2.2 Semantic Interoperability $\quad 9$

4.2.3 Organizational Interoperability 9

$\begin{array}{ll}4.3 & \text { Influencing Factors } \\ \end{array}$

4.3.1 Legal Factors $\quad 11$

4.3.2 Political Factors $\quad 11$

$\begin{array}{ll}\text { 4.3.3 Sociocultural Factors } & 12\end{array}$

$5 \quad$ Addressing the e-Government Interoperability Problem 13

$\begin{array}{lll}5.1 & \text { Interoperability Is Contextual } & 13\end{array}$

5.1.1 Public Services in Countries with Poor Infrastructures 13

5.1.2 Public Services in Developed Countries 13

$\begin{array}{ll}\text { 5.1.3 Public Services in Highly Connected Countries } & 14\end{array}$

$\begin{array}{lll}5.2 & \text { Addressing Interoperability Requirements } & 14\end{array}$

5.2.1 Addressing Technical Interoperability 15

5.2.2 Addressing Semantic Interoperability 17

$\begin{array}{ll}\text { 5.2.3 Addressing Organizational Interoperability } & 18\end{array}$

$\begin{array}{ll}\text { 5.2.4 Addressing Influencing Factors } & 18\end{array}$

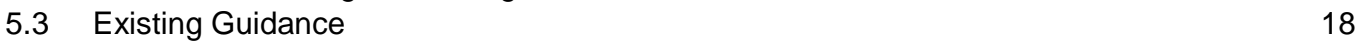

6 Conclusion $r$

$\begin{array}{lr}\text { References } & 21\end{array}$ 
CMU/SEI-2011-TN-014 | ii 


\section{List of Figures}

Figure 1: Interoperability Levels $\quad 9$

Figure 2: e-Government Interoperability Model 10 
CMU/SEI-2011-TN-014 | iv 


\section{Abstract}

Enabling e-government systems to interoperate provides many benefits, including improved efficiency, transparency, accountability, and access, as well as coordination of services at lower costs. However, repeated failures to build working systems show that the task is not only difficult but also poorly understood. This report describes a proposed model for understanding interoperability in the e-government context. With this model, system developers should characterize interoperability in six dimensions: technical, semantic, and organizational, as well as legal, political, and sociocultural. This report also presents guidance on how to address interoperability requirements and describes challenges that policy makers and system developers face in achieving interoperability in e-government systems. 
CMU/SEI-2011-TN-014 | vi 


\section{Introduction}

The term e-government is broadly defined as the use of information and communication technologies to support the business of government, such as providing or enhancing public services or managing internal government operations. Its benefits include improved efficiency, transparency, accountability, and access as well as coordination of services at lower costs. However, the task of delivering these benefits is not only difficult but also poorly understood. Our research suggests that interoperability is a fundamental barrier to achieving the benefits of e-government. We believe that a better understanding of the context and relevant issues will help resolve the difficulties many governments have in achieving these benefits.

While many governments have addressed interoperability as primarily a technical issue, the full range of the interoperability problem has other facets and is influenced by a variety of sources, especially in the public service context. To address the entirety of the interoperability challenge, we need to consider technical factors such as data semantics and process standardization as well as nontechnical factors such as legal, political, and social issues.

The purpose of this report is to explain the challenges associated with achieving interoperability in e-government systems in order to provide stakeholders of such systems a better understanding of the context and thus a better chance to succeed in building them. Section 2 discusses the egovernment context. Section 3 explains the problem of interoperability. Section 4 proposes a model for understanding interoperability in the e-government context. Section 5 analyzes how to solve the different facets of the interoperability problem and presents an overview of existing guidance on this topic. 


\section{The e-Government Context}

\subsection{What Is e-Government?}

There are many definitions of e-government; the following are representative:

the use of information and communication technologies (ICTs) to improve the activities of public sector organizations [eGovernment for Development Information Exchange 2008, para. 1]

the use of information technology to free movement of information to overcome the physical bounds of traditional paper and physical based systems [Pascual 2003, p. 5]

the use of technology to enhance the access to and delivery of government services to benefit citizens, business partners and employees [Deloitte Research 2000, p. 1]

There are common elements to these and other definitions, mainly automation, computerization, and the development of new processes to support government in the distribution of public services [Lungescu 2004].

In this report we define e-government as the use of ICTs to support the business of government, such as providing or enhancing public services or managing internal government operations. This definition is general enough to encompass not only different systems and technologies but also different contexts. For example, different countries have environments with varying levels of available technology, infrastructure, and social needs, and all these factors affect the design and implementation of e-government services. While Estonia may have sufficient infrastructure and social technological awareness to have Internet-enabled voting in government elections, the Philippines may find that providing simple technologies such as basic Internet access and photocopying as public services has a significant social impact [Lungescu 2004; Broache 2005; Alampay 2007, p. 4]. Our definition therefore covers technologies ranging from basic phone support to fully integrated government portals for all services [Malotaux 2007, p. 26].

\subsection{What Is e-Government Interoperability?}

Interoperability in the e-government context, like e-government itself, also has multiple definitions, such as

e-government interoperability, in its broad sense, is the ability of constituencies to work together. At a technical level, it is the ability of two or more diverse government information systems or components to meaningfully and seamlessly exchange information and use the information that has been exchanged. [UNDP 2007b, p. 1]

interoperability means the ability of information and communication technology (ICT) systems and of the business processes they support to exchange data and to enable the sharing of information and knowledge. [European Commission 2004, p. 5]

Most definitions capture the general idea behind interoperability but tend to focus on the technical aspects of interoperability, often reflecting the belief that interoperability is primarily a technical challenge [Pyarelal 2007, p. 18; Klischewski 2010, p. 1]. As a result, many initial efforts at build- 
ing e-government systems focus primarily on these technical challenges [UNDP 2007a, p. 10; CS Transform 2009, p. 3].

More recently, system designers have recognized that the entire interoperability problem consists of more than technical aspects [UNDP 2007a, p. 29; European Communities 2008, p. 4; Pardo 2008, p. 3]. Several efforts have begun to address the broader scope [CS Transform 2009, p. 3]. One of the largest e-government efforts, the European Commission's European Interoperability Framework (EIF), has redefined the concept of interoperability in the following more general way:

Interoperability is the ability of disparate and diverse organizations to interact towards mutually beneficial and agreed common goals, involving the sharing of information and knowledge between the organizations via the business processes they support, by means of the exchange of data between their respective information and communication technology (ICT) systems. [European Communities 2008, p. 5]

This definition acknowledges that interoperability encompasses a broader range of issues. Also, by explicitly citing "common goals," it acknowledges the existence of nontechnical influencing factors.

In this report we do not offer a formal definition of e-government interoperability but simply argue that achieving interoperability requires addressing a wide range of technical and nontechnical issues that are influenced by a number of factors. We discuss further the issues and factors involved in e-government interoperability in Section 3.

\subsection{What Are the Benefits of Interoperability in an e-Government Context?}

The benefits of achieving e-government interoperability are numerous and significant [European Communities 2008, p. 9]. From the standpoint of public services, we argue that addressing interoperability challenges will improve efficiency of service delivery, access to the services, coordination among existing services (resulting in further efficiency gains), and technology management and maintenance. In addition, the administration can avoid potential future costs such as inflexibility due to vendor lock-in and the high price of new development by leveraging existing systems in new ways [UNDP 2007a, pp. 1-2].

From the standpoint of policy makers, e-government interoperability will improve data gathering and parsing techniques, which will result in more efficient decision making that is based on more accurate information [UNDP 2007a, p. 1]. Improved interoperability will also enhance transparency and accountability, resulting in better overall governance [Lallana 2008, p. 2].

Finally, from the standpoint of relations between nations, interoperability can also promote cooperation by supporting cross-border efforts, for example, to interdict drug trafficking or facilitate legitimate trade [Lallana 2008, p. 2].

Despite these benefits, interoperability in the e-government context may have negative effects on security and privacy. However, we decided to consider security and privacy issues to be out of scope for this report. We chose to focus primarily on barriers to interoperability rather than on the drawbacks and potential adverse effects of interoperable e-government systems. 


\subsection{Why Is e-Government Interoperability Important?}

It is clear that achieving interoperability in the e-government context will improve public service in a variety of ways. We consider improving public services and general governance to be a key factor in meeting the United Nations Millennium Development goals [UNDP 2007b, p. 1; Secretary General, United Nations 2010, p. 15]. Specifically, improving transparency and accountability has a significant impact on promoting democracy [UNDP 2007b, p. 1].

From a different perspective, several examples of interoperability failures in public services demonstrate the need for higher levels of interoperability. The aftermath of the tsunami that struck Thailand in 2004 illustrates the high cost of failure:

December 26, 2004. 7:58 am. A thirty-foot-high wall of water-a tsunami-slams into the famed resort islands off Thailand's southern coast. In one tragic moment, thousands of lives are lost, and thousands more are missing.

In the race to identify victims and assist survivors, Thailand's government hits its own wall. Responding agencies and non-governmental groups are unable to share information vital to the rescue effort. Each uses different data and document formats. Relief is slowed; coordination is complicated. The need for common, open standards for disaster management was never more stark or compelling. [Open ePolicy Group 2005, p. 6]

Other more mundane situations highlight the cost to both the service provider and consumer:

There are 61 different benefit entitlement forms - the majority of which require the same standard information to be provided by benefit applicants. In most cases, links between the different benefit entitlements are not being made, meaning that some people may be missing entitlements they are due. [Varney 2006, p. 16]

A small business which has decided to recruit a new staff member is required to comply with a number of regulations. Currently, if this small business seeks guidance from the government, it will be faced with over 20 helplines, links to more than 25 additional websites, at least five codes of practice, and will need to be aware of 15 separate regulations on discrimination, not all of which are covered by explicit guidance. [Varney 2006, p. 16]

When we combine the benefits of successful interoperability with the costs of insufficient interoperability, the case for pursuing success in this field becomes clear. 


\section{The Interoperability Problem}

Interoperability is a complex problem. To enable interoperability in an e-government context, we must examine all its elements.

\subsection{What Is Interoperability?}

Interoperability is another term that has many definitions. Ford and colleagues provide a list of 34 different definitions [Ford 2007, p. 2] that cover a wide range of possible meanings:

- $\quad$ from the very general — “the ability of systems to work together” [Morris 2004, p. 5]

- to the very specific - “the ability of a set of communicating entities to (1) exchange specified state data and (2) operate on that state data according to specified, agreed-upon, operational semantics” [Morris 2004, p. 4]

- to the very targeted- "two-way radio: compatible communications paths (compatible frequencies, equipment and signaling), radio system coverage or adequate signal strength, and scalable capacity” [Wikipedia 2011]

Significant research has provided new ways to understand interoperability for many important stakeholders such as the computing community (significantly, the Institute of Electrical and Electronics Engineers), the health care industry, the U.S. Department of Defense, and software research institutions [IEEE 1990, Brownsword 2004, Ford 2007, Gibbons 2007, Lewis 2008]. This wealth of research implies that although there is significant interest in interoperability, there is little agreement on what it is. A potential reason for the many definitions and interpretations is that interoperability is situation dependent; its meaning can vary from technical to nontechnical, depending on the context [Ford 2007]. We believe that consensus about a definition can be reached only at a high level.

While researchers cannot agree on a common definition, most agree that we can break up the overall issue of interoperability into different types and/or levels [Tolk 2003a, 2003b; Brownsword 2004; Morris 2004; Ford 2007; Gibbons 2007; Lewis 2008; Wikipedia 2011]. System designers typically separate areas of concern (such as technical and nontechnical, as discussed in Section 4) by interoperability types and levels and organize them into interoperability models that present an overall perspective of interoperability in a given context.

\subsection{Interoperability Models}

Just as there are many definitions, there are multiple models for interoperability. The models break down the interoperability problem into different types, levels, and/or dimensions. The Levels of Information Systems Interoperability (LISI) model breaks down interoperability into different levels of connectivity between systems [C4ISR Architectures Working Group 1998]. The Organizational Interoperability Maturity Model (OIMM) and the Levels of Conceptual Interoperability Model (LCIM) build on the LISI model in different ways-the OIMM model through abstraction to command-and-control support and the LCIM model through data management - to bridge technical design and conceptual design [Clark 1999; Tolk 2003b; Morris 2004, 
pp. 6-8]. The NATO C3 Technical Architecture Reference Model for Interoperability focuses on operational effectiveness through data exchange ability [NATO 2003]. The Coalition Interoperability model builds on a number of other models to construct an interoperability model that covers technical and nontechnical concerns in the coalition environment [Tolk 2003a]. The Software Engineering Institute has proposed both a system of systems interoperability model and an "end-toend" interoperability model [Morris 2004, pp. 9-10; Lewis 2008]. The European Commission has proposed the EIF for e-government [UNDP 2007a, p. 9]. Finally, the United Nations Development Programme (UNDP) has proposed the Government Interoperability Framework (GIF) model [European Communities 2008, p. 20].

In general, developers define these models in terms of goals, types, and levels of interoperability:

- An interoperability goal refers to a communication capability of a given system. For example, the most basic goal of interoperability is the exchange of information. The goals in a given model may range from the most basic, such as the exchange of information, to very complex, such as harmonized strategies in the LCIM [Morris 2004]. The goals can also become more specific, depending on the granularity of the goals or the close relation to a particular domain of interest, which tends to result in specific goals related to that domain.

- A type of interoperability usually specifies a domain of interest (such as network interoperability) or a goal within a specific interoperability model. For example, protocol interoperability is a specific and domain-dependent type of interoperability proposed within the Coalition Interoperability model that pertains to the goal that the communication protocols used on a C4ISR ${ }^{1}$ network to support the necessary data exchange for the system [Tolk 2003a]. In contrast, the draft EIF 2.0 document defines technical interoperability as the broad area of all “technical aspects of linking computer systems and services” [European Communities 2008, p. 39].

- Many models of interoperability present levels or layers of interoperability. As in any layered model, each goal or type of interoperability within the model is complementary and builds on one another in a stack-like form. In other words, the model presents a base goal or type of interoperability and then places all of the other goals or types on top in an order that specifies that each goal or type requires all of the goals of the levels below to be met to achieve its goal.

Despite the similarities in how they are defined and structured, many of these models are unsuitable for defining a general interoperability model because of their domain-specific nature.

C4ISR stands for Command, Control, Communications, Computers, Intelligence, Surveillance, and Reconnaissance. A C4ISR network is any network that supports these activities. 


\section{A Proposed Model for Understanding Interoperability in the e-Government Context}

To understand interoperability in a general, domain-agnostic way, we propose a model that starts from the basic goals of interoperability. We then map these goals to levels, with the more complex goals mapped to higher levels of interoperability. Finally, we add the e-government context to the model as factors of influence.

For clarity, we define a communication to be some exchange of data between two participants through some medium that may or may not have meaning attached. We define participants as the ultimate senders and receivers of the data exchanged, that is, the entities that use the data in a manner other than simply facilitating the exchange. For example, in a scenario in which two humans communicate using cell phones, the humans are considered the participants and all of the hardware and software infrastructure elements facilitating the exchange are not considered participants as they only receive, process, and send the data to move it from one participant to the other. However, in such a system there are likely computer systems that monitor the conversation for audit logging, and thus the infrastructure may pass along direct or ancillary elements of the data exchange to these systems. Such systems, which use the data exchanged for purposes other than facilitating the communication, could also be considered participants, although whether or not they are considered active participants depends on the given context.

\subsection{Interoperability Goals}

There are three primary goals associated with achieving interoperability in any system (computer or otherwise): data exchange, meaning exchange, and process agreement.

\subsubsection{Data Exchange}

The first goal with respect to interoperability is basic data ${ }^{2}$ exchange. This particular goal deals not with meaning but rather with whether data can be exchanged at all. Examples of data exchange range from phone connections, email, and document exchanges to web pages and the automated exchange of data in computer-readable format. A computer system example would be the exchange of data between two computer systems in which there is agreement on the types and size of the data exchanged, such as a number with two digits to the right of the decimal point. In each of these examples, data can go back and forth without the participants having any knowledge of the meaning of the data.

\subsubsection{Meaning Exchange}

The second goal with respect to interoperability is the exchange of meaning (i.e., all participants in a given communication assign the same meaning to the information that is exchanged). To continue the example in the previous section, two computer systems agree not only on exchanging a

Even though the term information exchange is most common in interoperability models, we use data exchange to make clear that semantics or meaning is not exchanged at this level of interoperability. 
number with two digits to the right of the decimal point but also that the number corresponds to a price in U.S. currency and does not include tax.

Meaning exchange is fundamentally different from data exchange because of the aspect of misinterpretation. Data exchange either occurs or does not occur. Meaning exchange, however, is much more difficult because there is no implicit guarantee that all participants will interpret the meaning of the data in the same way. A well-publicized example illustrating this difficulty is the metric/imperial unit issue that caused the loss of the Mars Climate Orbiter spacecraft in 1999 [Lloyd 1999]. Even when two participants agree on a particular piece of data as a unit of distance, if both sides do not understand the specific type of unit in exactly the same way, there is potential for failure or even disaster.

\subsubsection{Process Agreement}

The third goal with respect to interoperability is agreement on how to act on information that has been exchanged (i.e., whether all participants in a given communication have the same understanding of how to act once they have exchanged information). Process agreement is a fundamentally different type of interoperability goal from the previous two types, data exchange and meaning exchange, because its focus shifts from the information exchanged to the actions taken by the participants once the information exchange has occurred.

To achieve process agreement, all participants must agree in advance about what to do with the data they receive in the exchange. To further extend the computer system example, assume that the exchanged price corresponds to the quoted price for a certain article and that the receiving party must acknowledge this price via a predefined acknowledgment message within 24 hours for the price to remain valid.

Process agreements are often complex and represent many of the problems that e-government efforts attempt to address. Lack of process agreement often manifests as a need for the consumer to provide the same information to multiple government services in response to a single event. For example, one documented case in the United Kingdom from 2004 showed that the process of a typical family making the necessary arrangements with the government to handle the death of a family member required 44 different interactions with government offices and was still unresolved after 180 days [Varney 2006, p. 16]. This example might be an extreme case, but improving the efficiency of and coordination between government agencies to minimize unreasonable overhead for citizens' use of public services is a primary benefit of e-government interoperability [UNDP 2007a, pp. 1-2; European Communities 2008, p. 11].

\subsection{Interoperability Levels}

The rationale for interoperability levels is to indicate how interoperability goals can build on each other to achieve more complex goals. On the basis of the interoperability goals presented in the previous section, we have established the following levels, as shown in Figure 1. 


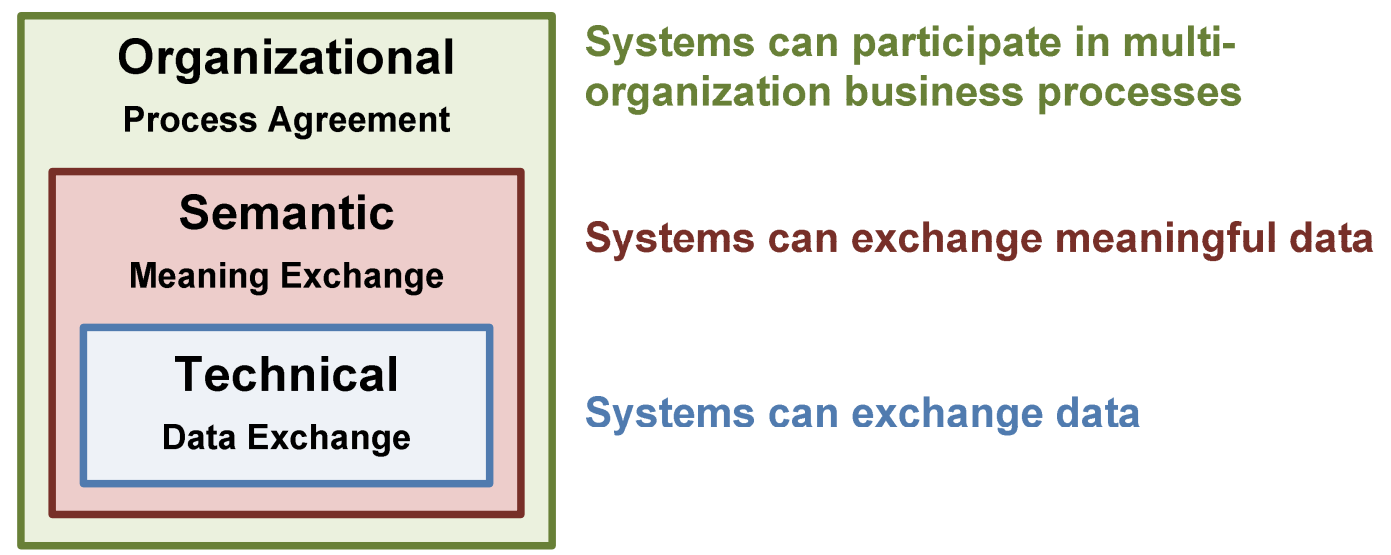

Figure 1: Interoperability Levels

\subsubsection{Technical Interoperability}

Technical interoperability maps to the goal of data exchange. We place technical interoperability at the base level because the exchange of data is at the root of all communication. In some of the more technically based interoperability models, this level is divided into sublevels that map to specific modes of communication and separate the data from the communication channel [Tolk 2003b, Lewis 2008]. The approach taken in existing e-government interoperability models is to abstract the details of the communication and have a single level, which is the approach that we have selected [UNDP 2007a, p. 9; European Communities 2008, p. 39].

\subsubsection{Semantic Interoperability}

Semantic interoperability maps to the goal of meaning exchange. We placed it above the technical interoperability level because in order to exchange meaning it is necessary to have already been successful at information exchange. This is consistent with many of the existing interoperability models [Gibbons 2007, pp. 14-15; UNDP 2007a, p. 9; European Communities 2008, p. 38; Lewis 2008; Stroetmann 2009; Wikipedia 2010b].

\subsubsection{Organizational Interoperability}

Organizational interoperability maps to the goal of process agreement. We placed it at the top level because process agreement cannot occur without both information exchange and meaning exchange supporting the communication to establish the process and the communication that contains the information for the recipient to act on.

The organizational interoperability level is consistent with some of the interoperability models, especially in the e-government context [UNDP 2007a, p. 9; European Communities 2008; Lewis 2008]. Some models describe this level in a more technical way as process interoperability [Gibbons 2007, p. 15]. Other models include process as an important concept with respect to interoperability but do not include a specific goal or level [Tolk 2003a, 2003b]. Although the term process interoperability describes the interoperability goal of process agreement more directly, organizational interoperability is a better term for the e-government context because it captures the scope of inter- and intra-organizational process alignment that is necessary to meet this interoperability goal. 


\subsection{Influencing Factors}

The e-government context is complex because it has to deal with legal, politics and policy, and sociocultural issues. For example, the independent nature of government agencies and conflicting leadership, policy, and financial priorities make it difficult to enable consolidation and cooperation in the pursuit of better citizen services [Biddick 2009].

In our proposed interoperability model, we represent this additional impact of legal, political (policy), and sociocultural issues as influencing factors. These factors are captured in this way and not as an additional level for these reasons:

- $\quad$ The impact of each is different, depending on the situation.

- They apply to almost any e-government system, regardless of the intended interoperability level.

For example, even a simple website that shares information with the public has to consider legal issues such as what information is considered public, political issues such as consistency with current policies and objectives, and sociocultural issues such as accessibility for non-English speakers.

From a system-developer perspective, these factors become an additional, critical dimension of the interoperability problem, and any e-government effort must address them. Reaching any interoperability level requires solutions to be compliant with legal, political, and sociocultural factors, as shown in the proposed interoperability model in Figure 2.

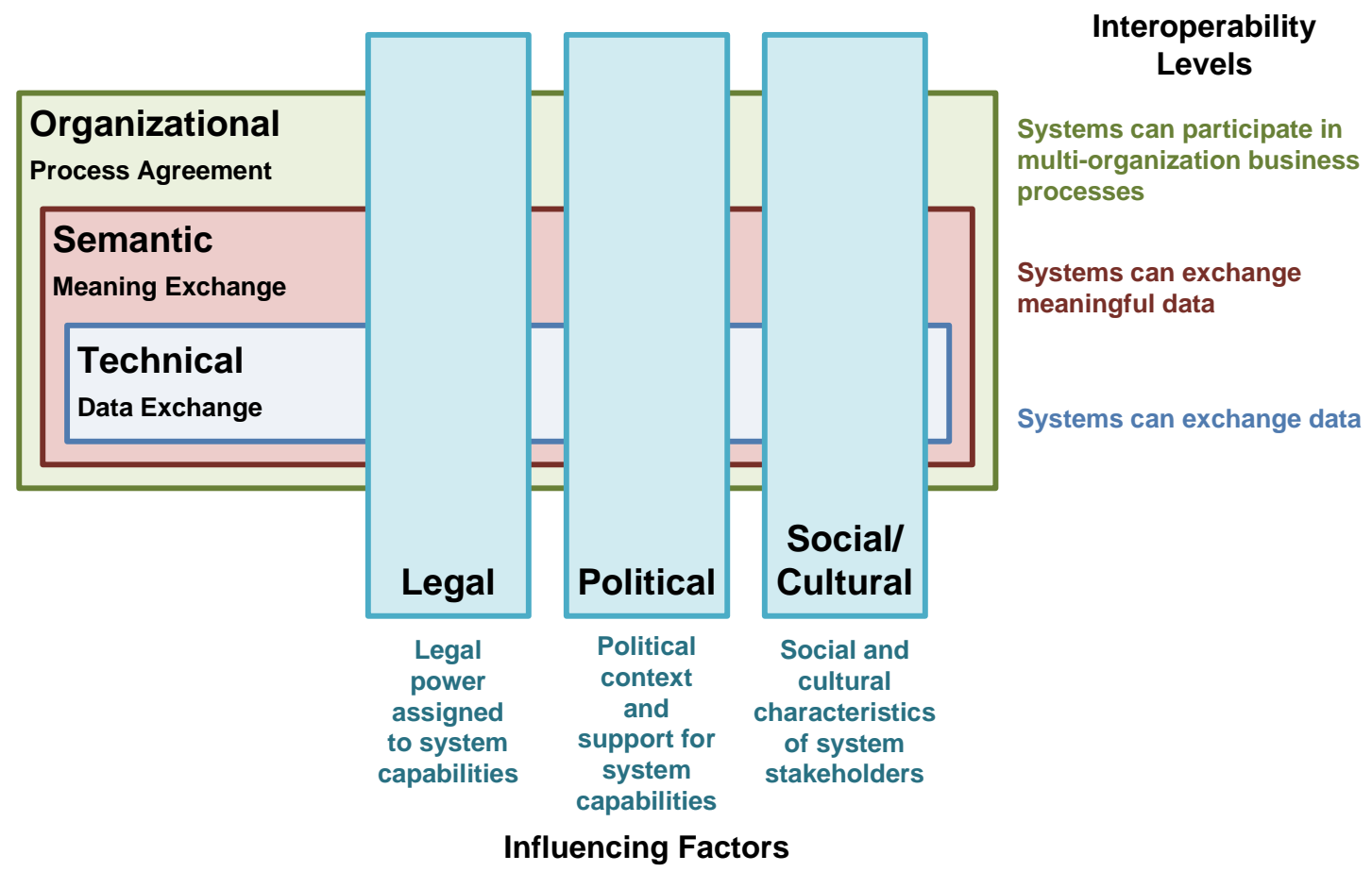

Figure 2: e-Government Interoperability Model 


\subsubsection{Legal Factors}

One of the primary concerns from a legal standpoint is the assignment of legal weight to the outputs of a given e-government system so that the system can support or replace existing manual public services [European Communities 2008, p. 33]. Identifying legal issues inherent to public services is critical not only to enable appropriate e-government services but also to identify services that are not appropriate for the e-government context. For example, the Department of Transportation for the U.S. state of Pennsylvania (PennDOT) does not offer online access to motor vehicle title-application forms, requiring registrants physically to appear at an Information Center with the necessary information, presumably for security reasons [PennDOT 2011a]. However, other services that potentially have less impact if they are compromised, such as license renewal or change of address, are offered directly through the department website [PennDOT 2011a].

Another area where legal concerns are important is the assignment of responsibility. All egovernment systems must fully comply with relevant laws, rules, and regulations, which can impose a high cost of failure. This can include regulations with respect to administrative law, intellectual property rights, and privacy and data-protection issues [European Communities 2008, p. 34]. The e-government systems must be legally responsible for these concerns, and this places a significant burden on the design, development, and maintenance of these systems. System designers must arrange for legal review of any potential failure of an e-government system to comply with laws and policies; determine the appropriate response to the failure; and, if necessary, carry out that response.

The draft 2.0 version of the EIF proposes an additional layer of interoperability called "legal interoperability" that addresses these concerns [European Communities 2008, p. 34]. This is a positive step toward recognizing the impact of legal concerns in the e-government context. However, creating a new level of interoperability for this layer is misleading because dealing with legal concerns does not result in addressing a new interoperability goal; rather, it influences the three interoperability goals already identified. As an example, legal concerns can affect the exchange of data by mandating that it is exchanged in a way that is secure and preserves privacy. In addition, legal concerns may affect the meaning of the information that is exchanged by mandating all information to be collected in a race-neutral way in order to prevent discrimination. Finally, legal concerns may affect process agreement by mandating hospital emergency rooms to provide stabilizing care to all who request it, resulting in processes that support this requirement.

\subsubsection{Political Factors}

The political context in which we introduce e-government systems is critically important to the success of any e-government interoperability effort. For example, the Gartner report on the EIF 2.0 update lists four general areas of concern that contain barriers to e-government interoperability: policy makers, administrations, IT departments, and accessibility [Malotaux 2007, pp. 20-21]. Within those four areas, only two note any technical issues, while coordination among different agencies and departments is a common theme across all areas. The Varney report lists six primary barriers to interoperability, five of which deal with agency coordination and budgetary issues [Varney 2006, pp. 17-18]. The draft EIF 2.0 document lists political context as its highest level of interoperability [European Communities 2008, p. 32]. This report acknowledges that guidance is 
difficult to define for this area of interest but that political support is critical for e-government interoperability success [European Communities 2008, p. 32].

The common theme in issues mentioned in these reports is political will. A government administration that has the political will and power to organize, manage, and fund an e-government interoperability project in a way that addresses all of the interrelated issues will have a much better chance for success. Without this critical element, it can be difficult to realize the level of cooperation and coordination among the participating government departments necessary to address the technical, semantic, and organizational interoperability challenges that an e-government project may have.

\subsubsection{Sociocultural Factors}

The final influencing factors that designers must consider when engaging in an e-government interoperability project are social and cultural concerns. The potential sources of impact in this area vary widely, depending on the context of the effort. For example, in ethnically diverse regions it may be necessary to deliver public services through different channels or customizable channels. An example of systems influenced by social and cultural concerns is the Spanish-language option that is available in the United States when calling most public service department phone numbers. The EIF mandates a "multi-channel approach" to compensate for socioeconomic disparities and multilingualism as a key factor for building interfaces to public services [European Commission 2004, p. 8]. Additionally, other sociocultural factors such as religion and language may also affect e-government interoperability efforts.

While social and cultural factors can affect all three levels of interoperability, we also stress that they are critical to another aspect-user adoption. Designers can develop services that meet the goals of the government and the needs of the citizens, but if the target users do not consider them accessible and usable, they may not adopt those services. In turn, the services will not realize their full potential. 


\section{Addressing the e-Government Interoperability Problem}

The context for every e-government project is different: different services require different technologies, different semantics, and different processes, and they are influenced by different factors. The combination of desired services and the context in which the provider will deliver them drives interoperability requirements. Although we can apply concepts such as maturity levels or frameworks to the e-government context, this can be misleading [Pardo 2008, p. 9]. While frameworks and models can certainly help us set expectations and focus on problems, assigning maturity levels often results in an implication that "higher is better" [Phillips 2009]. Instead, we argue that the correct approach is to find the level of interoperability that best delivers the specific public service or services being developed. Especially in e-government, interoperability is not necessarily machine to machine. There are many cases for which the solution is human to machine or even human to human. The following sections provide examples and guidance for addressing some of the challenges for systems interoperability in the e-government context.

\subsection{Interoperability Is Contextual}

To illustrate how different systems have different interoperability requirements, it is useful to examine a number of example systems that meet the needs of the communities they serve.

\subsubsection{Public Services in Countries with Poor Infrastructures}

One example of technologically basic yet effective public services is the Community e-Centers (CeC) in the Philippines [Alampay 2007, pp. 4-12]. CeCs are shared-access facilities that allow local residents to access basic services such as the Internet, photocopying, and distance-learning tools as well as support other government services in the education, business, and health areas. Because rural areas in the Philippines typically have limited computer and Internet access, the basic technological services that more connected countries take for granted are extremely useful in this context and represent a perfect fit.

A notable characteristic of the Philippines $\mathrm{CeC}$ effort is that the system does not really have to address the organizational and semantic interoperability levels. Technical interoperability, implemented by setting up the Internet connection and access machines, is sufficient for this effort. However, social and cultural factors certainly came into play in deciding on this solution (e.g., developing tutors and training programs because most $\mathrm{CeC}$ users do not know how to use computers). Political factors come into play with the budgeting and management of the distribution effort. The CeC system provides an example of the interplay of interoperability requirements and influencing factors that designers should consider to implement a successful public service.

\subsubsection{Public Services in Developed Countries}

In more developed countries, some government services are offered via web portals [Malotaux 2007, pp. 23-28]. An example of this type of service is the PennDOT website from Pennsylvania, which offers simple services such as change of address and scheduling of driver's license exams directly through the site [PennDOT 2011b]. To access any of the services, a user has to submit information to verify identity as well as any information required by the specific service (e.g., 
driver's license number, new and old address, test location, and test date). To facilitate this, the website has to be implemented to capture information from the user, validate the information, perform the necessary actions, and inform the user of the results. This represents the technical interoperability requirements of the system. The website specifies how to enter certain information (e.g., the format of the vehicle license plate number) and provides additional help to fill out the fields on the form. This is an example of semantic interoperability requirements to make sure that the user understands the meaning of the entered information. On the change of address form, there is an option to notify the county voter registration office of the change of address. This means there should be a semantic interoperability requirement between the two organizations such that they agree on the meaning of the information exchanged so that the service assigns the user to the proper voting site.

Although in some cases the underlying processes surrounding the transaction appear to be relatively simple - for example, a user submits identifying information and requested changes and PennDOT processes information and provides confirmation-both sides have process expectations that illustrate the organizational interoperability requirements of the system. In the case of a change of address, the user expects to receive a change of address stub in the mail within a number of days to use as a proof of address. In a more complex service that requires payment, such as renewing a driver's license, organizational interoperability requirements must exist between PennDOT and the online credit card processing companies. Finally, the system takes into account legal factors such as privacy requirements (a privacy statement is accessible from every page), social factors such as a common aversion to physically traveling to a DoT facility, and political factors such as funding and management of the department [Intelligenius Dot Net 2010].

\subsubsection{Public Services in Highly Connected Countries}

Highly connected countries, especially, provide examples of public services with high levels of interoperability. One of the most notable is the X-Road project run by the government of Estonia [Malotaux 2007, p. 26]. As one of the most technologically advanced countries in the European Union, Estonia has established the X-Road system as a primary gateway to services offered by all government agencies in the country [Lungescu 2004]. This has even enabled the institution of one of the first examples of online voting, a public service that has significant privacy and security implications [Broache 2005].

Although we do not have access to the actual interoperability requirements of the Estonian XRoad system, if we use the case of electronic voting, we can assume there are technical interoperability requirements to confirm that a voter's vote is registered, semantic interoperability requirements to make sure that the voter voted for the desired candidate, and organizational interoperability requirements to carry out the collection, protection, counting, and certification of the votes. The legal, political, and social influencing factors for such a service should be clear and would cause the service to fail if designers did not address them (e.g., accessibility to ensure that legal citizens can vote, party-neutral user interface that does not show any preference or privileged position for any party, and audit mechanisms to support recounts or challenges to election results).

\subsection{Addressing Interoperability Requirements}

Because every e-government system is context dependent, every project must identify and analyze its interoperability requirements and the influencing factors relevant to its own context. The fol- 
lowing sections present some guidance on how to address interoperability requirements and influencing factors.

\subsubsection{Addressing Technical Interoperability}

To enable information exchange at any level, governments must select compatible technology solutions. This can be as simple as standardizing a form or restricting communication to phone calls or as complex as selecting web service security standards. Regardless of the selected technology solution, service designers must consider a number of issues to ensure that the technology solution is appropriate. This effort should begin by examining how e-government stakeholders have historically attempted to solve the problem and identifying the issues relevant to their context.

\subsubsection{Technology Catalogs}

When governments first started thinking in earnest about e-government interoperability in the 1990s, the technology landscape presented some real challenges in the technical interoperability layer [CS Transform 2009]. In the United Kingdom, the government recognized that one of the key challenges was to restrain various ministries from creating custom and noninteroperable solutions, so the first U.K. eGovernment Interoperability Framework (eGIF) published in 2000 addressed that issue by stating that "by adopting Internet and World Wide Web standards, the Framework aligns government with the rest of industry” [Minister for the Cabinet Office 2001].

Numerous countries have followed the United Kingdom's lead over the past decade, establishing "standards catalogues" that contain approved technologies for use in a country's e-government systems [Hoel 2009]. These catalogs enable a country to establish some commonality in the technologies used by different services across different agencies or ministries. Using technical standards to constrain technology procurement across departments and agencies is a proven method for promoting technical interoperability among large numbers of interacting entities [Lewis 2008].

\subsubsection{Use of Open Standards}

A common theme in the e-government context is the use of open standards to promote interoperability [Pyarelal 2007, p. 18; UNDP 2007b, p. 3; Wattegama 2007; European Communities 2008, p. 53; Government of India 2008]. Although it is difficult to define open standard, many standards stakeholders do agree on several key attributes. For example, a group of the world's leading telecommunications and radio standards-setting organizations known as the Global Standards Collaboration has suggested the following attributes [Global Standards Collaboration 2009, International Telecommunication Union 2011]:

- The standard is developed, approved, and maintained by a collaborative consensus-based process.

- $\quad$ Such process is transparent.

- $\quad$ The process includes materially affected and interested parties. 
- The standard is subject to RAND/FRAND ${ }^{3}$ Intellectual Property Right (IPR) policies, which do not mandate, but may permit at the option of the IPR holder, licensing essential intellectual property without compensation.

- The standard is published and made available to the general public under reasonable terms (including for a reasonable fee or for free).

Open standards are important to governments because they can increase the number of compatible offerings (which leads to lower switching costs) and because wide stakeholder participation may increase the quality and suitability of the standard [European Communities 2008]. However, open standards are not always the solution because there will always be domains where open standards do not yet exist. So in some areas, at least for an interim period, governments may find themselves using so-called de facto standards that are controlled by a single company or small group of companies [European Communities 2008, Lewis 2008]. In addition, the open and consensusbased process that is typical of an open standard may not keep up with the rapid speed of innovation in the technology world. In the end, standards are successful if widely implemented, and wide implementation in turn depends on a number of factors that include the relevance of the standard, the process of adoption (open, transparent), and the quality of the documentation [European Communities 2008].

\subsubsection{Understanding Limitations of Standards}

Standards are clearly an important component of technical interoperability. However, we must stress the risks of placing too much emphasis on technical standards and the limitations of what a standards catalog will provide in the context of eGIFs.

First, the selection of technology standards will not guarantee semantic or organizational interoperability [Lewis 2008]. Even though there are languages for modeling information meaning and processes to support interoperation in these areas, the fundamental limitation is human agreement: All parties must agree on what a data point means and what to do with it. No current technology can make those decisions automatically, and it is unlikely that any technology ever will. We discuss this topic further in Section 5.2.2.

Second, there are risks in relying on standards to achieve technical interoperability. According to Lewis and colleagues, standards evolve, often break backward compatibility, are inconsistently specified, can become unstable or irrelevant, and can conflict or compete with other standards [Lewis 2008]. Also, mandating standards that are not yet mature enough for wide adoption can affect their evolution [CS Transform 2009, p. 3]. Finally, placing too much focus on standard selection can distract attention from the equally important effort of addressing semantic and organizational interoperability [CS Transform 2009, p. 3]. For example, a recent e-government effort in Egypt that utilized a technology-first approach resulted in significant infrastructure improvements but no actual public service improvements, primarily because of lack of "organizational readiness” to leverage the delivered technology [Klischewski 2010, p. 8].

Third, selecting a standard to solve a technical interoperability problem requires agreement, or at least rough consensus, and as a result it may not be possible for governments prospectively to list

3 RAND/FRAND stands for reasonable and nondiscriminatory/fair, reasonable, and nondiscriminatory [Phipps 2010]. 
standards for all domains of interaction among the government, citizens, and businesses. This is especially true in nascent areas of technology, such as education:

Standards catalogues are a means by which governments may lead and coordinate development in certain domains. We have highlighted that in the [learning education technology] domain this might not be effective, and alternative approaches should be found. [Hoel 2009, p. 241]

Finally, researchers and marketers are increasingly discussing the role that these standards lists play in today's world.

Much of the technical content in many IFs [interoperability frameworks] is at a level of detail which, nowadays, is unnecessary. The market has matured significantly in recent years, so the solutions to many of what were previously seen as technical barriers to interoperability are now "designed in" to a wide choice of competitive, commercial products. [CS Transform 2009, p. 3]

\subsubsection{Understanding and Preparing for Evolution of Standards}

Technology changes over time and precipitates corresponding changes in any standards selected for an e-government effort. Thus, standards will need to be updated even if they are appropriate for the context at the time they are implemented. To fully leverage a technology standard, adopting organizations must actively manage the impact of changes to the standard on the systems in which it is used, which involves deciding when to adopt, upgrade, switch, and/or discontinue use. Failing to compensate for changes in the standard can result in a number of potential issues, such as incompatibilities with newer products and the need for workarounds so that existing products retain their value [Lewis 2008].

\subsubsection{Addressing Semantic Interoperability}

To support semantic interoperability in a technological context, public service providers have to agree on several characteristics of the data to be exchanged, including data attributes such as

- $\quad$ units (e.g., metric versus imperial units)

- $\quad$ validity (e.g., retirement-related information is valid only if the age of the person is greater than 65)

- $\quad$ time period (e.g., a policy may not apply if an event occurred during a certain period of time)

Achieving semantic interoperability is a difficult problem that is largely unsolved within the egovernment context [European Communities 2008, p. 38]. Stakeholders typically achieve semantic interoperability through direct negotiation until they reach a consensus. One common approach to building this consensus is to construct an ontology or set of ontologies, which are basically data models that define the data items that are exchanged-including the exact meaning and structure assigned to them —and the relationships between data items. Technologies that support ontology generation include OWL and XBRL [Wikipedia 2010a].

There are limitations in the use of ontologies and other semantic interoperability solutions. First, while data models generally cover only a single domain or area of concern, the typical egovernment system will probably need to understand multiple areas of concern to operate correctly. For example, an emergency response system must be concerned about map data, weather data, 
logistics data, health data, and citizen data. Each of these areas of concern may represent the same data in a different way. Second, consumers of data models require different levels of detail, aggregation, and/or summarization. For example, a data model for meteorological data can be extremely detailed to support a scientist conducting studies on weather patterns and effects, whereas the typical consumer may be interested only in today's weather forecast. Third, areas of concern tend to evolve, requiring maintenance of existing data models and in some cases generation of new ones. Finally, it can be difficult for any community of interest to reach consensus on any area because people tend to interpret information in slightly different ways.

\subsubsection{Addressing Organizational Interoperability}

To enable organizational interoperability in the e-government context, public service providers have to agree on not only what information is exchanged, when it is exchanged, and how it is exchanged but also what to do with it when it is exchanged. Stakeholders typically achieve organizational interoperability in a manner similar to semantic interoperability, by negotiating directly to come to a consensus on the processes they will use.

Addressing organizational interoperability is also similar to addressing semantic interoperability: The process is primarily manual, and a few tools are available to automate the process. For example, BPEL and YAWL are languages that can be used to model processes for web services [OASIS 2007, YAWL Foundation 2009]. For a more general approach, BPMN can be used to graphically model business processes [OMG 2011].

Processes evolve in ways similar to data models and technological standards and thus incur the same maintenance costs. Agreement by communities of interest on processes can also be hard to reach for the same reasons and also because different organizations tend to use different business processes to create competitive advantages. ${ }^{4}$ Different organizations also have different (and sometimes directly conflicting) goals, so there may be scenarios in which technical and semantic interoperability exists between two government entities, but because of their competing goals the organizations will not agree to work together.

\subsubsection{Addressing Influencing Factors}

Even though necessary for successful implementation of e-government systems, guidance for dealing with legal, political, and sociocultural influencing factors is beyond the scope of this report. Some newer guidance on e-government interoperability discusses these factors, such as the draft EIF 2.0 document [European Communities 2008, p. 38].

\subsection{Existing Guidance}

Interoperability in the e-government domain is becoming a more popular research topic as more governments attempt to stand up their own systems and stakeholders better understand the scope of the challenge. The UNDP has published several documents outlining GIFs [Varney 2006, p. 2; Lallana 2007; UNDP 2007a, 2007b]. These guides are a good place to start framing the problem and provide a good overview of e-government interoperability efforts across the globe. However,

While competitive advantage is certainly a driver for developing different processes in the private sector, this is less of a concern in the e-government domain. However, it may still become a factor in business-government interactions. 
readers should be cautioned that these documents tend to focus on, and result in, interoperability efforts mainly at the technical level [UNDP 2007a, CS Transform 2009].

Another significant effort is the European Commission's EIF, which was released initially in 2004 and is currently undergoing a revision [European Commission 2004, European Communities 2008]. While the first version of the EIF provided a similar overview of the interoperability challenges as the GIF, draft 2.0 of the EIF is much more robust in addressing more than just technical interoperability. As we discussed earlier, although we disagree with its classification of legal and political factors as levels of interoperability, the new version of the EIF effectively highlights the importance of these factors and provides useful guidance for addressing them.

In developing specific strategies, countries such as the United Kingdom, the Netherlands, and Estonia have made significant progress on the e-government interoperability challenge [Malotaux 2007, pp. 22-27]. One survey has also found that Austria and Malta lead the way in sophistication and availability [Wauters 2007]. The efforts in these countries, as well as a number of others, can help serve as a guide for other efforts.

Finally, the United States and Canada have taken a different approach to e-government interoperability by leveraging enterprise architecture (EA) frameworks such as the Zachman Framework and the Open Group Architecture Framework [Open Group 2008; Zachman International Enterprise Institute 2008; CS Transform 2009, p. 3; Inside Architecture Blog 2009]. The U.S. government also provides a number of guidance documents on EA frameworks currently in use in egovernment efforts [White House OMB 2011]. 


\section{Conclusion}

Systems interoperability is contextual. A corollary to this statement is that interoperability is not a characteristic of a single system but rather a characteristic of the relationship between two or more systems in a particular context. The context in which systems have to interoperate shapes the requirements that each individual system has to satisfy in order for it to interoperate with other systems. Thus, developers need to plan system components around both technical and nontechnical aspects of interoperability. A development team can analyze interoperability in any context along technical, semantic, and organizational dimensions, but the diversity and complexity of the legal, political, and sociocultural dimensions of the e-government context make interoperability challenging for e-government systems.

The model proposed in this report captures the differences between technical, semantic, and organizational interoperability while highlighting the crosscutting impact of legal, political, and sociocultural issues as influencing factors. The goal of this model is to reinforce that developers need to characterize interoperability in the e-government context along the six dimensions of the model so that they can understand, discuss, and analyze it. If e-government system designers better understand the problem of interoperability and account for context-dependent influencing factors, we predict that more e-government efforts will succeed. 


\section{References}

URLs are valid as of the publication date of this document.

\section{[Alampay 2007]}

Alampay, Gigo \& Umali, Joel. High Impact, Pro-Poor e-Governance Applications: Identifying "Killer Applications" and Best Practice Models of e-Governance Through Community e-Centers in the Philippines. United Nations Development Programme, 2007.

\section{[Biddick 2009]}

Biddick, Michael. “Government IT Priorities,” InformationWeek Government. http://www.informationweek.com/news/government/enterprise-architecture/218500752 (July 18, 2009).

\section{[Broache 2005]}

Broache, Anne. "Estonia Pulls Off Nationwide Net Voting," CNET News. http://news.cnet.com/Estonia-pulls-off-nationwide-Net-voting/2100-1028_3-5898115.html (Oct. 19, 2005).

\section{[Brownsword 2004]}

Brownsword, L., Carney, D. J., Fisher, D., Lewis, G., Morris, E. J., Place, R. R., Smith, J., Wrage, L., \& Meyers, B. C. Current Perspectives on Interoperability (CMU/SEI-2004-TR-009). Software Engineering Institute, Carnegie Mellon University, 2004.

http://www.sei.cmu.edu/library/abstracts/reports/04tr009.cfm

\section{[C4ISR Architectures Working Group 1998]}

C4ISR Architectures Working Group. Levels of Information Systems Interoperability. U.S. DoD, OSD (C3I), CIO, Director for Architecture and Interoperability, 1998.

http://www.eng.auburn.edu/ hamilton/security/DODAF/LISI.pdf

\section{[Clark 1999]}

Clark, T. \& Jones, R. “Organisational Interoperability Maturity Model for C2.” Proceedings of the 1999 Command and Control Research and Technology Symposium. Newport, RI, June 1999. CASOS, 1999. http://www.dodccrp.org/events/1999_CCRTS/pdf_files/track_5/049clark.pdf

\section{[CS Transform 2009]}

CS Transform. Beyond Interoperability: A New Policy Framework for e-Government. CS Transform, 2009.

\section{[Deloitte Research 2000]}

Deloitte Research. At the Dawn of e-Government: The Citizen as Customer. Deloitte \& Touche, 2000. http://www.epractice.eu/files/At\%20the\%20Dawn\%20of\%20e-Government\%20\%20The\%20Citizen\%20as\%20Customer.pdf 


\section{[eGovernment for Development Information Exchange 2008]}

eGovernment for Development Information Exchange. What Is eGovernment? University of Manchester's Institute for Development Policy and Management, 2008.

http://www.egov4dev.org/success/definitions.shtml

\section{[European Commission 2004]}

European Commission. European Interoperability Framework for Pan-European eGovernment Services. Official Publications of the European Communities, 2004.

\section{[European Communities 2008]}

European Communities. Draft Document as Basis for EIF 2.0. Official Publications of the European Communities, 2008.

\section{[Ford 2007]}

Ford, Thomas C., Colombi, John M., Graham, Scott R., \& Jacques, David R. “A Survey on Interoperability Measurement." Proceedings of the 12th International Command and Control Research and Technology Symposium. Newport, RI, June 2007. http://www.dtic.mil/cgi-

bin/GetTRDoc?Location=U2\&doc=GetTRDoc.pdf\&AD=ADA481314

\section{[Gibbons 2007]}

Gibbons, Patricia, et al. Coming to Terms: Scoping Interoperability for Health Care. EHR Interoperability Work Group, 2007.

\section{[Global Standards Collaboration 2009]}

Global Standards Collaboration. "Resolution GSC-14/24: (IPRWG) Open Standards (Reaffirmed).” Presented at the 14th Global Standards Collaboration meeting, July 2009.

http://www.itu.int/dms_pub/itu-t/oth/21/05/T2105000011002400MSWE.doc

\section{[Government of India 2008]}

Government of India. Policy on Open Standards for E-Governance. Ministry of Communications \& Information Technology, 2008. http://egovstandards.gov.in/policy/policy-on-open-standardsfor-e-

governance/policy_doc_and_manual_used_in_printing_recd_on_Nov_12.pdf/at_download/file

\section{[Hoel 2009]}

Hoel, Tore \& Hollins, Paul. "Could European eGovernment Policy Initiatives, in Effect, Be Stifling the Development of Learning Technologies?” 239-241. Proceedings of the 9th IEEE International Conference on Advanced Learning Technologies. Riga, Latvia, July 2009. IEEE Computer Society Press, 2009. http://doi.ieeecomputersociety.org/10.1109/ICALT.2009.171

\section{[IEEE 1990]}

Institute of Electrical and Electronics Engineers. IEEE Standard Computer Dictionary: A Compilation of IEEE Standard Computer Glossaries. IEEE Computer Society Press, 1990.

\section{[Inside Architecture Blog 2009]}

Inside Architecture Blog. A First Look at TOGAF 9.0.

http://blogs.msdn.com/nickmalik/archive/2009/02/02/a-first-look-at-togaf-9-0.aspx (Feb. 2, 2009). 


\section{[Intelligenius Dot Net 2010]}

Intelligenius Dot Net. Why Do People Hate DMV. http://www.intelligenius.net/why-do-peoplehate-dmv (May 18, 2010).

\section{[International Telecommunication Union 2011]}

International Telecommunication Union. Global Standards Collaboration.

http://www.itu.int/ITU-T/gsc (Jan. 12, 2011).

\section{[Klischewski 2010]}

Klischewski, Ralf \& Abubakr, Ranwa. "Can e-Government Adopters Benefit from a TechnologyFirst Approach? The Case of Egypt Embarking on Service-Oriented Architecture.” Proceedings of the 43rd Hawaii International Conference on System Sciences. Koloa, HI, Jan. 2010. IEEE Computer Society Press, 2010. http://doi.ieeecomputersociety.org/10.1109/HICSS.2010.92

\section{[Lallana 2007]}

Lallana, Emmanuel C. e-Government Interoperability: A Review of Government Interoperability Frameworks in Selected Countries. United Nations Development Programme, 2007.

\section{[Lallana 2008]}

Lallana, Emmanuel C. e-Government Interoperability. United Nations Development Programme, 2008.

\section{[Lewis 2008]}

Lewis, Grace, Morris, Edwin, Simanta, Soumya, \& Wrage, Lutz. "Why Standards Are Not Enough to Guarantee End-to-End Interoperability,” 164-173. Proceedings of the Seventh International Conference on Composition-Based Software Systems (ICCBSS 2008). Madrid, Spain, Feb. 2008. IEEE Computer Society Press, 2008.

\section{[Lloyd 1999]}

Lloyd, Robin. "Metric Mishap Caused Loss of Mars Orbiter.” CNN.com. http://www.cnn.com/TECH/space/9909/30/mars.metric.02 (Sep. 30, 1999).

\section{[Lungescu 2004]}

Lungescu, Dana. “Tiny Estonia Leads Internet Revolution.” BBC News. http://news.bbc.co.uk/2/hi/europe/3603943.stm (Apr. 7, 2004).

\section{[Malotaux 2007]}

Malotaux, Michiel, van der Harst, Guido, Achtsivassilis, Jorgos, \& Hahndiek, Fred. Preparation for Update European Interoperability Framework 2.0—Final Report (Engagement 221402470). Gartner, 2007.

\section{[Morris 2004]}

Morris, Edwin, Levine, Linda, Meyers, Craig, Place, Patrick, \& Plakosh, Daniel. Systems of Systems Interoperability (SOSI): Final Report (CMU/SEI-2004-TR-004). Software Engineering Institute, Carnegie Mellon University, 2004.

http://www.sei.cmu.edu/library/abstracts/reports/04tr004.cfm 


\section{[Minister for the Cabinet Office 2001]}

Minister for the Cabinet Office. The e-Government Interoperability Framework. Cabinet Office, 2001. http://interim.cabinetoffice.gov.uk/media/259067/e-GIF4Pt1_2002-04-25.pdf

\section{[NATO 2003]}

NATO. NATO C3 Technical Architecture (NC3TA), Version 4.0 (NATO Allied Data Publication 34). NATO, 2003. http://www.nato.int/docu/standard.htm

\section{[OMG 2011]}

OMG. Business Process Model and Notation (Version 2.0) (OMG Doc. No. formal/2011-01-03). Object Management Group, 2011. http://www.omg.org/spec/BPMN/2.0/PDF

\section{[Open Group 2008]}

The Open Group. Welcome to TOGAF-The Open Group Architecture Framework. http://www.opengroup.org/architecture/togaf8-doc/arch/toc.html (1999-2008).

\section{[Open ePolicy Group 2005]}

Open ePolicy Group. Roadmap for Open ICT Ecosystems. Berkman Center for Internet \& Society at Harvard Law School, 2005.

\section{[OASIS 2007]}

Organization for the Advancement of Structured Information Standards. Web Services Business Process Execution Language Version 2.0. OASIS, 2007. http://docs.oasisopen.org/wsbpel/2.0/wsbpel-v2.0.pdf

\section{[Pardo 2008]}

Pardo, Theresa A. \& Burke, G. Brian. Improving Government Interoperability: A Capability Framework for Government Managers. Center for Technology in Government, SUNY Albany, 2008.

\section{[Pascual 2003]}

Pascual, Patricia, J. “Definition,” 5-9. e-Government. eAsean Task Force, UNDP-APDIP, 2003.

\section{[PennDOT 2011a]}

Pennsylvania Department of Motor Vehicles. Motor Vehicle Information for New Residents. http://www.dmv.state.pa.us/new_residents/motor_vehicle.shtml (2011).

\section{[PennDOT 2011b]}

Pennsylvania Department of Motor Vehicles. Online Services Center. http://www.dmv.state.pa.us/centers/OnlineServicesCenter.shtml (2011).

\section{[Phillips 2009]}

Phillips, Mike. The Value of High Maturity to the Customer. http://www.sei.cmu.edu/library/abstracts/news-at-sei/cmmiinfocus.cfm (Jan. 1, 2009). 


\section{[Phipps 2010]}

Phipps, Simon. RAND: Not So Reasonable. Computerworld UK.

http://blogs.computerworlduk.com/simon-says/2010/11/rand-not-so-reasonable/index.htm (Nov. 17, 2010).

\section{[Pyarelal 2007]}

Pyarelal, Suchitra. "Interoperability and Open Standards for e-Governance.” egov (Sep. 1, 2007): 17-19.

\section{[Secretary General, United Nations 2010]}

Secretary General, United Nations. Keeping the Promise: A Forward-Looking Review to Promote an Agreed Action Agenda to Achieve the MDGs by 2015. United Nations, 2010.

\section{[Stroetmann 2009]}

Stroetmann, Veli N., et al. Semantic Interoperability for Better Health and Safer Healthcare. SemanticHEALTH, European Commission, 2009.

\section{[Tolk 2003a]}

Tolk, A. "Beyond Technical Interoperability-Introducing a Reference Model for Measures of Merit for Coalition Interoperability." Proceedings of the 8th International Command and Control Research and Technology Symposium (ICCRTS). Washington, DC, 2003. http://www.dodccrp.org/events/8th_ICCRTS/Pres/track_1/2_1530tolk.pdf

\section{[Tolk 2003b]}

Tolk, A. \& Muguira, J. A. “The Levels of Conceptual Interoperability Model.” Presented at the 2003 Fall Simulation Interoperability Workshop, Orlando, FL, Sep. 2003.

\section{[UNDP 2007a]}

UNDP. e-Government Interoperability: Guide. United Nations Development Programme, 2007.

\section{[UNDP 2007b]}

UNDP. e-Government Interoperability: Overview. United Nations Development Programme, 2007.

\section{[Varney 2006]}

Varney, David. Service Transformation: A Better Service for Citizens and Businesses, a Better Deal for the Taxpayer. The Stationery Office, 2006.

\section{[Wattegama 2007]}

Wattegama, Chanuka \& Pauso, Kathryn. Government Interoperability Frameworks in an Open Standards Environment (APDIP e-Note 20). United Nations APC/ICT, 2007.

\section{[Wauters 2007]}

Wauters, Patrick, Nijskens, Matthias, \& Tiebout, Jeroen. The User Challenge: Benchmarking the Supply of Online Public Services. European Commission/Capgemini, 2007.

http://ec.europa.eu/information_society/eeurope/i2010/docs/benchmarking/egov_benchmark_200 7.pdf 


\section{[White House OMB 2011]}

White House Office of Management and Budget. Federal Enterprise Architecture.

http://www.whitehouse.gov/omb/e-gov/fea (2011).

[Wikipedia 2010a]

Wikipedia. Ontology Engineering. http://en.wikipedia.org/wiki/Ontology_engineering (Feb. 19, 2010).

\section{[Wikipedia 2010b]}

Wikipedia. Semantic Interoperability. http://en.wikipedia.org/wiki/Semantic_interoperability (Feb. 23, 2010).

\section{[Wikipedia 2011]}

Wikipedia. Interoperability. http://en.wikipedia.org/wiki/Interoperability (Apr. 26, 2011).

[YAWL Foundation 2009]

YAWL Foundation. YAWL: Yet Another Workflow Language. http://yawlfoundation.org (Oct. 4, 2009).

\section{[Zachman International Enterprise Institute 2008]}

Zachman International Enterprise Institute. The Zachman Framework: The Official Concise Definition. http://test.zachmaninternational.com/index.php/the-zachman-framework (2008). 


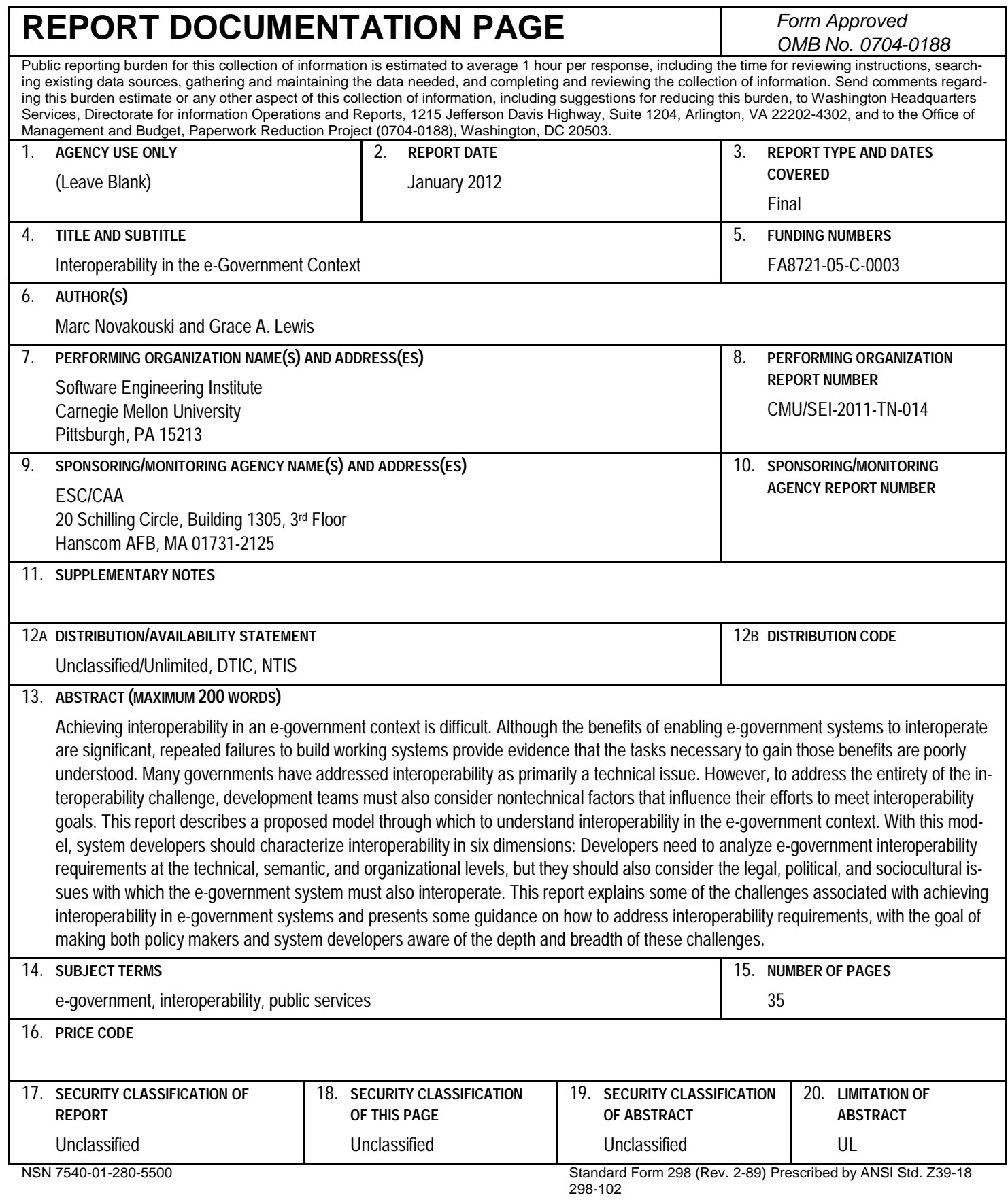

